\title{
Direct Yaw-Moment Control of All-Wheel-Independent-Drive Electric Vehicles with Network-Induced Delays through Parameter-Dependent Fuzzy SMC Approach
}

\author{
Wanke Cao, ${ }^{1,2}$ Zhiyin Liu, $^{2}$ Yuhua Chang, ${ }^{2}$ and Antoni Szumanowski ${ }^{2}$ \\ ${ }^{1}$ The National Engineering Laboratory for Electric Vehicles and the Collaborative Innovation Center of Electric Vehicles in Beijing, \\ School of Mechanical Engineering, Beijing Institute of Technology (BIT), Beijing 100081, China \\ ${ }^{2}$ The Department of Multisource Propulsion System, Faculty of Automotive and Construction Machinery Engineering, \\ Warsaw University of Technology (WUT), Narbutta 84, Warsaw 02-524, Poland
}

Correspondence should be addressed to Wanke Cao; caowanke@bit.edu.cn

Received 25 August 2016; Revised 20 November 2016; Accepted 20 December 2016; Published 22 January 2017

Academic Editor: Quanmin Zhu

Copyright (C) 2017 Wanke Cao et al. This is an open access article distributed under the Creative Commons Attribution License, which permits unrestricted use, distribution, and reproduction in any medium, provided the original work is properly cited.

\begin{abstract}
This paper investigates the robust direct yaw-moment control (DYC) through parameter-dependent fuzzy sliding mode control (SMC) approach for all-wheel-independent-drive electric vehicles (AWID-EVs) subject to network-induced delays. AWID-EVs have obvious advantages in terms of DYC over the traditional centralized-drive vehicles. However it is one of the most principal issues for AWID-EVs to ensure the robustness of DYC. Furthermore, the network-induced delays would also reduce control performance of DYC and even deteriorate the EV system. To ensure robustness of DYC and deal with network-induced delays, a parameter-dependent fuzzy sliding mode control (FSMC) method based on the real-time information of vehicle states and delays is proposed in this paper. The results of cosimulations with Simulink ${ }^{\circledR}$ and CarSim ${ }^{\circledR}$ demonstrate the effectiveness of the proposed controller. Moreover, the results of comparison with a conventional FSMC controller illustrate the strength of explicitly dealing with network-induced delays.
\end{abstract}

\section{Introduction}

In recent years, all-wheel-independent-drive electric vehicles (AWID-EVs) have attracted increasing research efforts from both the academia and industry [1-3]. Equipped by advanced electric motors with more accurate and quicker torque generations than internal combustion engine (ICE) and hydraulic braking systems, AWID-EVs have obvious advantages in terms of direct yaw-moment control (DYC) through flexible differential driving/braking functions over traditional centralized drive vehicles [1,3-6]. Plenty of existing studies have focused on the more flexible DYC and its integration control with active steering for AWID-EVs [2, 713]. However, considering the presence of model uncertainties, system parameter variations and external disturbances such as road rough or wind gust, it is one of the most principal issues for AWID-EVs to ensure the robustness of DYC.
To improve and ensure the robustness of DYC, in the existing lateral dynamics control strategies of AWIDEVs, sliding mode control (SMC) has been widely adopted, which is robust and suitable for nonlinear systems such as vehicles. Goodarzi and Esmailzadeh used a sliding mode controller in low-level control to improve the robustness of vehicle dynamics control system for AWID-EVs [1]. Li et al. employed a sliding mode controller in the main loop to offer enough robustness for an integrated vehicle chassis control system based on DYC, active steering, and active stabilizer [14]. Wang and Longoria designed three sliding mode controllers to ensure control system robustness in a new coordinated-reconfigurable vehicle dynamics control strategy for AWID-EVs [15] and [16,17] presented a terminal sliding mode control method to improve the robustness of yaw rate tracking control and torque distribution control. But, in all of these aforementioned control strategies based on 


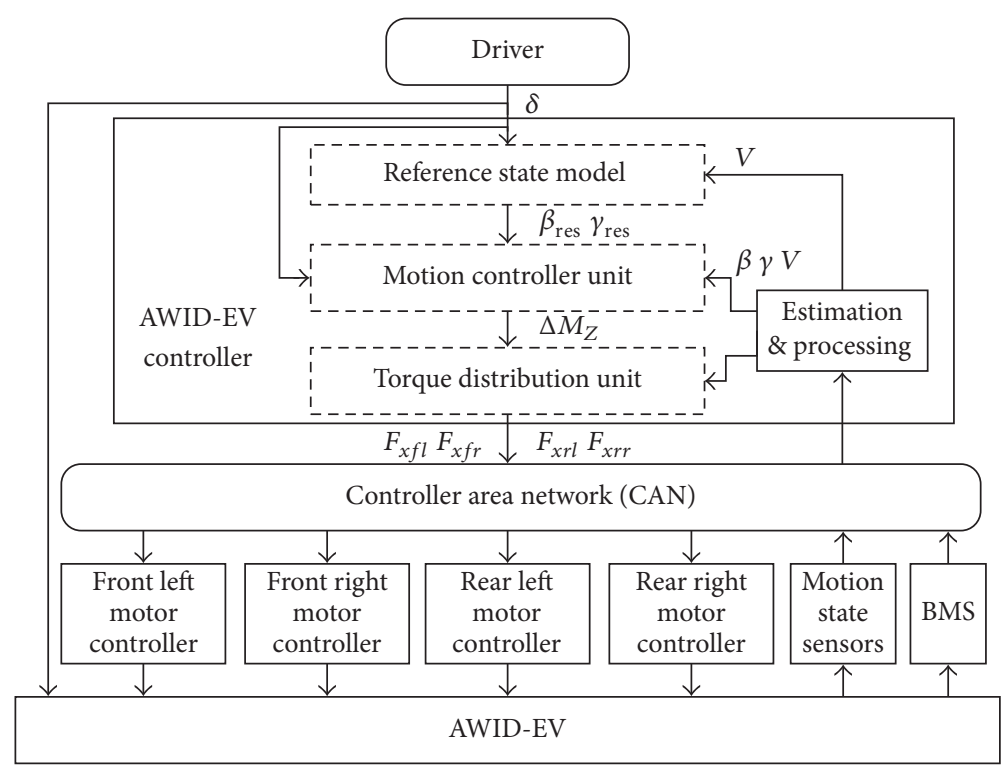

FIGURE 1: Overall structure for DYC of networked AWID-EVs.

SMC, the interference from electronic control systems such as networked-induced delays is not considered.

However, in a modern AWID-EV, the control signals from controllers and the measurements from sensors are usually exchanged through an in-vehicle communication network, for example, controller area network (CAN) or FlexRay [2]. In other words, a modern AWID-EV is a networked control system (NCS) rather than a conventional centralized control system $[2,7,9,10]$. Thus, the network-induced delays cannot be ignored. According to these research results in $[2,7,9,10]$, the network-induced delays caused by CAN could reduce the control performance of DYC and even deteriorate the EV system. Some researchers proposed $H_{\mathrm{\infty}}$-based linear quadratic regulator (LQR) control method against CAN network delays as in $[2,7,10]$. However, research on SMCbased DYC of AWID-EVs is rare.

Furthermore, as a variable structure control technology, SMC is more vulnerable to network-induced delays than continuous control technologies such as LQR or PID $[18,19]$. There are numerous approaches to improve SMC. Among these approaches, the state-dependent boundary layer tuning method [20] has been widely used to improve the robustness of SMC. However the conventional state-dependent boundary layer tuning method is not sufficiently effective to deal with network-induced delay.

The main work is as follows: firstly, the network- induced delays are explicitly considered in the DYC through SMC control method. Considering that the network-induced delays lead to a challenging problem for the DYC based on SMC, the chattering problem of SMC caused by the delays is analyzed in detail and the delays are determined with a command-first scheme, which is a more accurate method than the existing approaches. Furthermore, a parameterdependent fuzzy sliding mode control (FSMC) method based on the real-time information of vehicle states and system delays is proposed to ensure the robustness of DYC for AWID-EVs against network-induced delays.

The remaining sections of this paper are organized as follows: In Section 2, problem formulation is described containing overall structure for DYC of networked AWIDEVs, control-oriented vehicle lateral dynamics model, and reference state model. The negative impact that resulted from NCS on the lateral dynamics model of AWID-EVs is also analyzed in detail in this section. In Section 3, an integrated statedependent and delay-dependent fuzzy SMC is proposed to improve the robustness of DYC for networked AWID-EVs. In Section 4 , the results of cosimulations with Matlab $^{\circledR} /$ Simulink and CarSim are demonstrated. Conclusions are summarized in Section 5.

\section{Problem Formulation}

2.1. Overall Structure for DYC of Networked AWID-EVs. According to vehicle dynamics, the main working principle of the DYC of AWID-EVs is to keep the vehicle lateral motion state variables such as the yaw rate and the slip angle tracking the reference states by using the external yaw moment [21], which is directly generated by active longitude tire forces distribution of all wheels. As shown in Figure 1, a typical overall structure for DYC of networked 4-wheel-independent drive vehicles mainly consists of AWID-EV controller, controller area network (CAN), 4 motor controllers, motion state sensors, and BMS. The overall control system is integrated by CAN.

The DYC function is implemented by AWID-EV controller, which is usually designed as a hierarchical controller including reference state model, motion controller unit, torque distribution unit, and estimation and processing unit as in Figure 1. The reference state model is used to solve the 


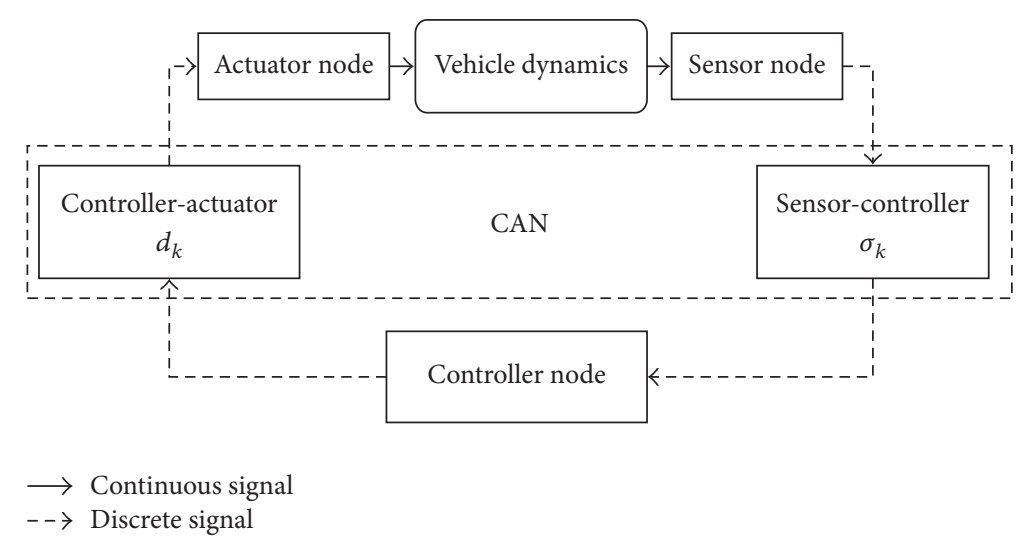

FIGURE 2: General structure of the NCS for DYC of AWID-EVs.

reference states such as the reference sideslip angle $\beta_{\text {res }}$ and the reference yaw rate $\gamma_{\text {res }}$ according to vehicle speed $V$ and the front wheel steering angle $\delta$ from the driver. The reference states indicate the desired motion state by the driver. The motion controller unit is used to calculate the external yawmoment $\Delta M_{z}$ to keep the sideslip angle $\beta$ and the yaw rate $\gamma$ tracking the reference states. The torque distribution unit is used to solve the longitude forces $F_{x f l}, F_{x f r}, F_{x r l}$, and $F_{x r r}$ for 4 motors according to the $\Delta M_{z}$. The estimation and processing unit is used to measure or estimate states such as $V, \beta, \gamma$.

In this study, the motion controller unit, which influences the system robustness against network-induced delays, will be studied, whereas the reference state model, torque distribution unit, and estimation and processing unit are simplified.

2.2. Control-Oriented Vehicle Lateral Dynamics Model. As shown in Figure 3, a two-degree-of-freedom (2-DOF) vehicle model, which has been widely studied as the control-oriented vehicle lateral dynamics model in various researches on DYC of vehicles [2,21], is used in the paper, where CG is the center of gravity; $m$ is the vehicle mass; $I_{z}$ is the vehicle yaw inertia; $M_{z}$ is the yaw moment; $F_{x f}$ and $F_{x r}$ are the longitude tire forces of front and rear wheels, respectively; $F_{y f}$ and $F_{y r}$ are the lateral tire forces of front and rear wheels, respectively; $\alpha_{f}$ and $\alpha_{r}$ are the slip angle of front and rear wheels, respectively.

With the 2-DOF vehicle model, the state-space formulation of control-oriented vehicle lateral dynamics model for DYC of AWID-EVs is expressed as follows [10]:

$$
\dot{x}=A x+B u+E \delta,
$$

where

$$
\begin{aligned}
x & =\left[\begin{array}{ll}
\beta & \gamma
\end{array}\right]^{T}, \\
u & =\Delta M_{z}, \\
A & =\left[\begin{array}{cc}
-2 \frac{c_{f}+c_{r}}{m V} & -2 \frac{c_{f} l_{f}-c_{r} l_{r}}{m V^{2}}-1 \\
-2 \frac{c_{f} l_{f}-c_{r} l_{r}}{I_{z}} & -2 \frac{c_{f} l_{f}^{2}+c_{r} l_{r}^{2}}{I_{z} V}
\end{array}\right], \\
B & =\left[\begin{array}{c}
0 \\
\frac{1}{I_{z}}
\end{array}\right],
\end{aligned}
$$

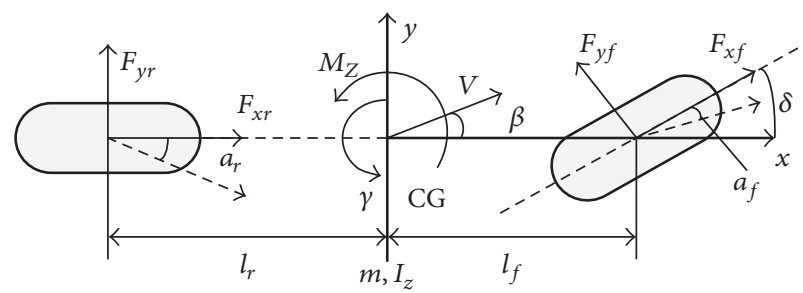

FIgURE 3: 2-DOF model of control-oriented vehicle lateral dynamics.

$$
E=\left[\begin{array}{c}
\frac{2 c_{f}}{m V} \\
\frac{2 c_{f} l_{f}}{I_{z}}
\end{array}\right] .
$$

$c_{f}$ and $c_{r}$ are the cornering stiffness of the front and rear tires, respectively.

2.3. Reference State Model. In vehicle lateral motion control, the desired sideslip angle is generally selected to be zero to ensure vehicle stability, while the desired yaw rate is usually defined to ensure good handling performance [10]. A widespread expression of the desired yaw rate is described in $[2,10]$. Therefore, the reference state model can be written as follows:

$$
r=R \delta,
$$

where

$$
\begin{aligned}
& r=\left[\begin{array}{c}
\beta_{\text {res }} \\
\gamma_{\text {res }}
\end{array}\right], \\
& R=\left[0 \frac{V}{l_{f}+l_{r}+m V^{2}\left(c_{r} l_{r}-c_{f} l_{f}\right) / 2 c_{f} c_{r}\left(l_{f}+l_{r}\right)}\right]^{T} .
\end{aligned}
$$

2.4. The Impact Resulted from NCS on Vehicle Lateral Dynamics Model. Firstly, without loss of generality as in [22], it is possible to make following assumption. In the NCS of DYC for AWID-EVs shown in Figure 2, the sensor node 


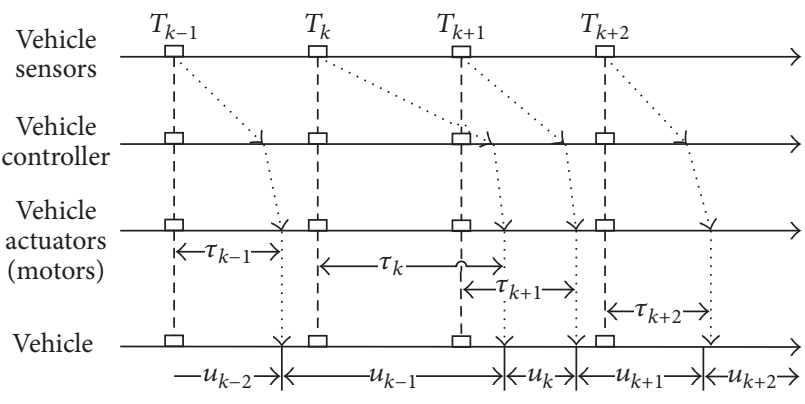

FIGURE 4: The network-induced delays.

periodically samples the vehicle states with fixed period $T_{s}$, the controller node and the actuator node operate in event-driven mode which means a task will be immediately implemented once a message arrives via CAN, and the task implementation time in each node is ignored. With such assumption and without considering network-induced delays, the NCS of DYC for AWID-EVs runs like an ideal centralized control system with fixed sampling period $T_{s}$. The control-oriented discrete-time model of the vehicle lateral dynamics along with reference state model can be written as [2]

$$
\begin{aligned}
x_{k+1} & =A_{d} x_{k}+B_{d} u_{k}+E_{d} \delta_{k}, \\
r_{k} & =R_{d} \delta_{k},
\end{aligned}
$$

where

$$
\begin{aligned}
A_{d} & =e^{A T_{s}}, \\
R_{d} & =R, \\
B_{d} & =\int_{0}^{T_{s}} e^{A\left(T_{s}-\theta\right)} d \theta \cdot B, \\
E_{d} & =\int_{0}^{T_{s}} e^{A\left(T_{s}-\theta\right)} d \theta \cdot E
\end{aligned}
$$

with $x_{k}, \delta_{k}, u_{k}$, and $r_{k}$ indicating the state vector, steering angle vector, control input vector, and the reference state vector at time $k T_{s}$, respectively.

Secondly, considering the network-induced delays and the same assumption mentioned above, the control input $u$ will be delayed by CAN as shown in Figure 4 .

Thus, the control input $u$ of the vehicle model at time $t$ can be expressed as follows [22]:

$$
u(t)=u_{k}, \quad \forall t \in\left[k T_{s}+\tau_{k},(k+1) T_{s}+\tau_{k+1}\right] .
$$

If the delay $\tau_{k}$ is expressed as

$$
\tau_{k}=(\Upsilon+v) T_{s},
$$

where $\Upsilon \in Z_{+}$and $v \in R_{[0,1)}$.
Then, the control-oriented discrete-time model of the vehicle lateral dynamics with network-induced delays can be expressed as follows [2]:

$$
\begin{aligned}
x_{k+1}= & A_{d} x_{k}+E_{d} \delta_{k}+B_{d} u_{k}+\Delta_{0, k}\left(u_{k-1}-u_{k}\right) \\
& +\Delta_{1, k}\left(u_{k-2}-u_{k-1}\right)+\cdots \\
& +\Delta_{\Upsilon, k}\left(u_{k-\Upsilon-1}-u_{k-\Upsilon}\right) \\
= & A_{d} x_{k}+E_{d} \delta_{k}+B_{d} u_{k}+\sum_{i=0}^{\Upsilon} \Delta_{i, k}\left(u_{k-i-1}-u_{k-i}\right),
\end{aligned}
$$

where the coefficient of each disturbance element induced by network-induced delays is expressed as follows [2]:

$$
\begin{aligned}
& \Delta_{i, k} \\
& \quad= \begin{cases}0, & \tau_{k-i}-i \cdot T_{s} \leq 0 \\
\int_{0}^{\tau_{k-i}-i \cdot T_{s}} e^{A\left(T_{s}-\theta\right)} d \theta \cdot B, & 0 \leq \tau_{k-i}-i \cdot T_{s} \leq T_{s} \\
\int_{0}^{T_{s}} e^{A\left(T_{s}-\theta\right)} d \theta \cdot B, & T_{s} \leq \tau_{k-i}-i \cdot T_{s} .\end{cases}
\end{aligned}
$$

For analyzing, expression (9) is rewritten as follows:

$$
x_{k+1}=A_{d} x_{k}+B_{d} u_{k}+E_{d} \delta_{k}+f(k),
$$

where the disturbance item

$$
f(k)=\sum_{i=0}^{\Upsilon} \Delta_{i, k}\left(u_{k-i-1}-u_{k-i}\right) .
$$

$f(k)$ is the function of the network-induced delay $\tau$ and the input $u$.

Thus, the control-oriented model of vehicle lateral dynamics for networked AWID-EVs is described as a discrete-time model with the disturbance elements caused by network-induced delays. 


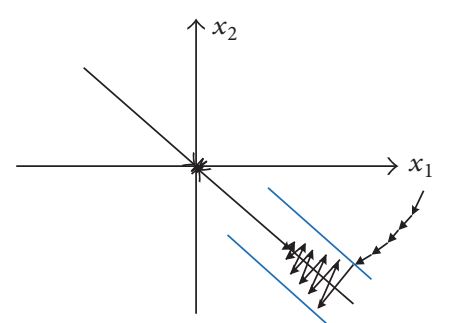

FIGURE 5: Trajectories of quasi-sliding mode.

\section{Controller Design}

3.1. Sliding Mode Controller Design for DYC of 4 WID-EV. Firstly, without considering network-induce delays, a general SMC for the discrete-time model (5) is designed. According to the typical design methodology of an general SMC [18], the sliding mode surface can be defined as

$$
s(x)=c^{T}(x-r)=c^{T} e .
$$

$e$ denotes the tracing error of motion states and $c^{T}=\left[c_{1} c_{2}\right]$ is the weight coefficient of elements of $e$.

A reach law has been widely used $[15,18]$, which is written as

$$
\begin{aligned}
s_{k+1}-s_{k}=-q T_{s} s_{k}-\varepsilon T_{s} \operatorname{sgn}\left(s_{k}\right), & \\
\varepsilon & >0, q \geq 0,1-q T_{s}>0,
\end{aligned}
$$

where $s_{k}$ denotes $s\left(x_{k}\right)$ at the time $T_{k}$.

With the reach law (14), the control law can be solved as follows:

$$
\begin{aligned}
u_{k} & =-\left(c^{T} B_{d}\right)^{-1}\left\{c^{T} A_{d} x_{k}+c^{T} E_{d} \delta_{k}-c^{T} r_{k+1}\right. \\
& -c^{T}\left(x_{k}-r_{k}\right)+q T_{s} c^{T}\left(x_{k}-r_{k}\right) \\
& \left.+\varepsilon T_{s} \operatorname{sgn}\left[c^{T}\left(x_{k}-r_{k}\right)\right]\right\} .
\end{aligned}
$$

However, according to the research in [18], for a discretetime system, the state trajectory hardly occurs on the sliding mode surface (13) but zigzags around the sliding mode surface cause a quasi-sliding mode with a quasi-sliding mode band (QSMB) as in Figure 5. The QSMB is expressed as follows [18]:

$$
\left\{x|| s(x) \mid<\frac{\varepsilon T_{s}}{1-q T_{s}}\right\} .
$$

In order to avoid the chattering phenomenon in the QSMB, a boundary layer technique $[1,14]$ is usually adopted by defining a saturation function $\operatorname{sat}\left(s_{k}\right)$ instead of $\operatorname{sgn}\left(s_{k}\right)$ in (14) and (15)

$$
\text { sat }\left(s_{k}\right)= \begin{cases}1, & \text { if } s_{k}>w_{\mathrm{bl}} \\ k s_{k}, & \text { if }\left|s_{k}\right| \leq w_{\mathrm{bl}}, \quad k=\frac{1}{w_{\mathrm{bl}}} \\ -1, & \text { if } s_{k}>-w_{\mathrm{bl}},\end{cases}
$$

where $w_{\mathrm{bl}}$ is the boundary layer width.

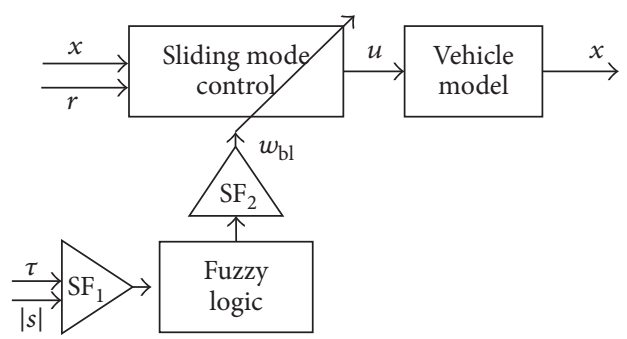

FIGURE 6: Fuzzy sliding mode controller for DYC of AWID-EV.

Thus, the reach law (14) and control law (15) can be rewritten as

$$
\begin{aligned}
& s_{k+1}-s_{k}=-q T_{s} s_{k}-\varepsilon T_{s} \operatorname{sat}\left(s_{k}\right), \\
& u_{k}=-\left(c^{T} B_{d}\right)^{-1}\left\{c^{T} A_{d} x_{k}+c^{T} E_{d} \delta_{k}-c^{T} r_{k+1}\right. \\
& -c^{T}\left(x_{k}-r_{k}\right)+q T_{s} c^{T}\left(x_{k}-r_{k}\right) \\
& \left.+\varepsilon T_{s} \operatorname{sat}\left[c^{T}\left(x_{k}-r_{k}\right)\right]\right\} .
\end{aligned}
$$

According to the expression (16), it is necessary to tune the boundary layer width $w_{\mathrm{bl}}$ based on the dynamics of $s(x)$ in the controller design stage. When the control law (19) is used for the discrete-time system (5), the $s(x)$ dynamics can be expressed as [18]:

$$
s_{k+1}=s_{k}-q T_{s} s_{k}-\varepsilon T_{s} \text { sat }\left(s_{k}\right) .
$$

The $s(x)$ dynamics can be solved by (5) and (12).

However, when the control law (19) is used for the DYC of networked AWID-EVs, according to formulas (11), (13), (14), and (19), the $s(x)$ dynamics will be changed as follows:

$$
s_{k+1}=s_{k}-q T_{s} s_{k}-\varepsilon T_{s} \text { sat }\left(s_{k}\right)-c^{T} f(k) .
$$

Comparing (21) with (20), the disturbance item $c^{T} f(k)$, which is caused by network-induced delays, will impose a new uncertainty item on the $s(x)$ dynamics and will result in adverse impact on the robustness of DYC.

3.2. Integrated State-Dependent and Delay-Dependent Sliding Mode Controller Design. A state-dependent boundary layer tuning method [20], which can tune the boundary layer width actively according to the dynamic state such as $s(x)$ instead of a fixed boundary layer, has been widely used to improve the robustness of SMC in the real-time system applications [20].

However, according to (21), the network-induced delays cause the uncertainty of the $s(x)$ dynamics. Consequently, it is reasonable to create an integrated state-dependent and delaydependent method to tune the boundary layer width for SMC dynamically (see Figure 6). 
TABLE 1: Fuzzy linguistic variable value terms.

\begin{tabular}{lc}
\hline Name & Description (relative value) \\
\hline NB & Negative big \\
NS & Negative small \\
ZE & Zero \\
PS & Positive small \\
PB & Positive big \\
PB1+ & Positive big + level 1 \\
PB2+ & Positive big + level 2 \\
PB3+ & Positive big + level 3 \\
PB4+ & Positive big + level 4 \\
\hline
\end{tabular}

However, according to expressions (10), (12), and (21), the mathematic function between the $s(x)$ and the networkinduced delay $\tau$ is complicated nonlinear. It is too difficult to be solved online in general in-vehicle ECUs. Thus, a fuzzy logic unit is designed to deal with the complicated nonlinear mathematic problem as in Figure 6.

3.3. Fuzzy Logic Unit Design for the Integrated StateDependent and Delay-Dependent Method. As shown in Figure 6, the fuzzy logic unit is used to solve the boundary layer width $w_{\mathrm{bl}}$ according to the state norm $|s|$ and the network-induced delay $\tau$. Thus the fuzzy logic unit has two input values and one unique output value, which are, respectively, defined as follows.

Input 1

$|S| \in\{\mathrm{NB}, \mathrm{NS}, \mathrm{ZE}, \mathrm{PS}, \mathrm{PB}\}$

Input 2

$$
\tau \in\{\mathrm{NB}, \mathrm{NS}, \mathrm{ZE}, \mathrm{PS}, \mathrm{PB}\}
$$

Output

$$
\begin{aligned}
& W_{\mathrm{bl}} \\
& \quad \in\{\mathrm{NB}, \mathrm{NS}, \mathrm{ZE}, \mathrm{PS}, \mathrm{PB}, \mathrm{PB} 1+, \mathrm{PB} 2+, \mathrm{PB} 3+, \mathrm{PB} 4+\}
\end{aligned}
$$

And the fuzzy linguistic variable values are defined in Table 1. As shown in Figure 7, the triangular membership functions are used for the fuzzification of the two input variables and the one output variable. The scaling factors $\mathrm{SF}_{1}$ and $\mathrm{SF}_{2}$ (see Figure 6), which are tuned at the design stage by trial and extensive simulations performed in this study, are used to map the actual values of the input and output variables to their fuzzified values [23]. The rule base for the proposed fuzzy logic unit is described in Table 2.

The variable domains such as the inputs $|s| \in[0,0.5]$ and $\tau \in[0,20]$ and the output $w_{\mathrm{bl}} \in[0.6,1.4]$ are selected based on the simulation results with a high-fidelity full-vehicle model in CarSim and Matlab in this study.
TABLE 2: Rule base of the fuzzy logic unit.

\begin{tabular}{lcc}
\hline$|S|$ & $\boldsymbol{\tau}$ & $W_{\mathrm{bl}}$ \\
\hline $\mathrm{NB}$ & $\mathrm{NB}$ & $\mathrm{NB}$ \\
$\mathrm{NS}$ & $\mathrm{NB}$ & $\mathrm{NS}$ \\
$\mathrm{ZE}$ & $\mathrm{NB}$ & $\mathrm{ZE}$ \\
$\mathrm{PS}$ & $\mathrm{NB}$ & $\mathrm{PS}$ \\
$\mathrm{PB}$ & $\mathrm{NB}$ & $\mathrm{PB}$ \\
$\mathrm{NB}$ & $\mathrm{PS}$ & $\mathrm{PS}$ \\
$\mathrm{NS}$ & $\mathrm{PS}$ & $\mathrm{PB}$ \\
$\mathrm{ZE}$ & $\mathrm{PS}$ & $\mathrm{PB} 1+$ \\
$\mathrm{PS}$ & $\mathrm{PS}$ & $\mathrm{PB} 2+$ \\
$\mathrm{PB}$ & $\mathrm{PS}$ & $\mathrm{PB} 3+$ \\
$\mathrm{NB}$ & $\mathrm{NS}$ & $\mathrm{NS}$ \\
$\mathrm{NS}$ & $\mathrm{NS}$ & $\mathrm{ZE}$ \\
$\mathrm{ZE}$ & $\mathrm{NS}$ & $\mathrm{PS}$ \\
$\mathrm{PS}$ & $\mathrm{NS}$ & $\mathrm{PB}$ \\
$\mathrm{PB}$ & $\mathrm{NS}$ & $\mathrm{PB} 1+$ \\
$\mathrm{NB}$ & $\mathrm{PB}$ & $\mathrm{PB}$ \\
$\mathrm{NS}$ & $\mathrm{PB}$ & $\mathrm{PB} 1+$ \\
$\mathrm{ZE}$ & $\mathrm{PB}$ & $\mathrm{PB} 2+$ \\
$\mathrm{PS}$ & $\mathrm{PB}$ & $\mathrm{PB}+$ \\
$\mathrm{PB}$ & $\mathrm{PB}$ & $\mathrm{PBP} 4+$ \\
$\mathrm{NB}$ & $\mathrm{ZE}$ & $\mathrm{ZE}$ \\
$\mathrm{NS}$ & $\mathrm{ZE}$ & $\mathrm{PS}$ \\
$\mathrm{ZE}$ & $\mathrm{ZE}$ & $\mathrm{PB}$ \\
$\mathrm{PS}$ & $\mathrm{ZE} 1+$ \\
$\mathrm{PB}$ & $\mathrm{ZE}$ & $\mathrm{PB} 1+$ \\
\hline & & \\
& & $\mathrm{NE}$
\end{tabular}

The fuzzy unit employs the Mamdani Fuzzy Inference System (FIS), which is described by the following schema:

$$
\begin{aligned}
& \text { IF }|S| \text { is } A, \tau \text { is } B, \text { THEN } W_{\mathrm{bl}} \text { is } C . \\
& \text { IF }|S| \text { is } A^{\prime}, \tau \text { is } B^{\prime}, \text { THEN } W_{\mathrm{bl}} \text { is } C^{\prime},
\end{aligned}
$$

where $A, A^{\prime}, B, B^{\prime}, C$, and $C^{\prime}$ are fuzzy values defined as the input and output variables, respectively. The centre of area method is used in the defuzzification to solve $W_{\mathrm{bl}}$.

The rule base in detail between the inputs and the outputs is shown in Figure 8. Thus, once the state norm $|s|$ and the network-induced delay $\tau$ are known, the boundary layer width can be calculated by the fuzzy unit, and these rules could be easily implemented into the microprocessor of vehicle controller with a look-up mode. According to definition (13), the state norm $|s|$ is known, and the unknown network-induced delay $\tau$ will be discussed in the following section.

3.4. Determination of the Network-Induced Time Delay. To implement the proposed method, the network-induced delay $\tau$ should be determined. According to the assumption above (see Figures 2 and 4 ), the network-induced delay $\tau_{k}$, which consists of the delays in both the forward and feedback links in the $k$ th cycle, can be expressed as follows:

$$
\tau_{k}=d_{k}+\sigma_{k}
$$



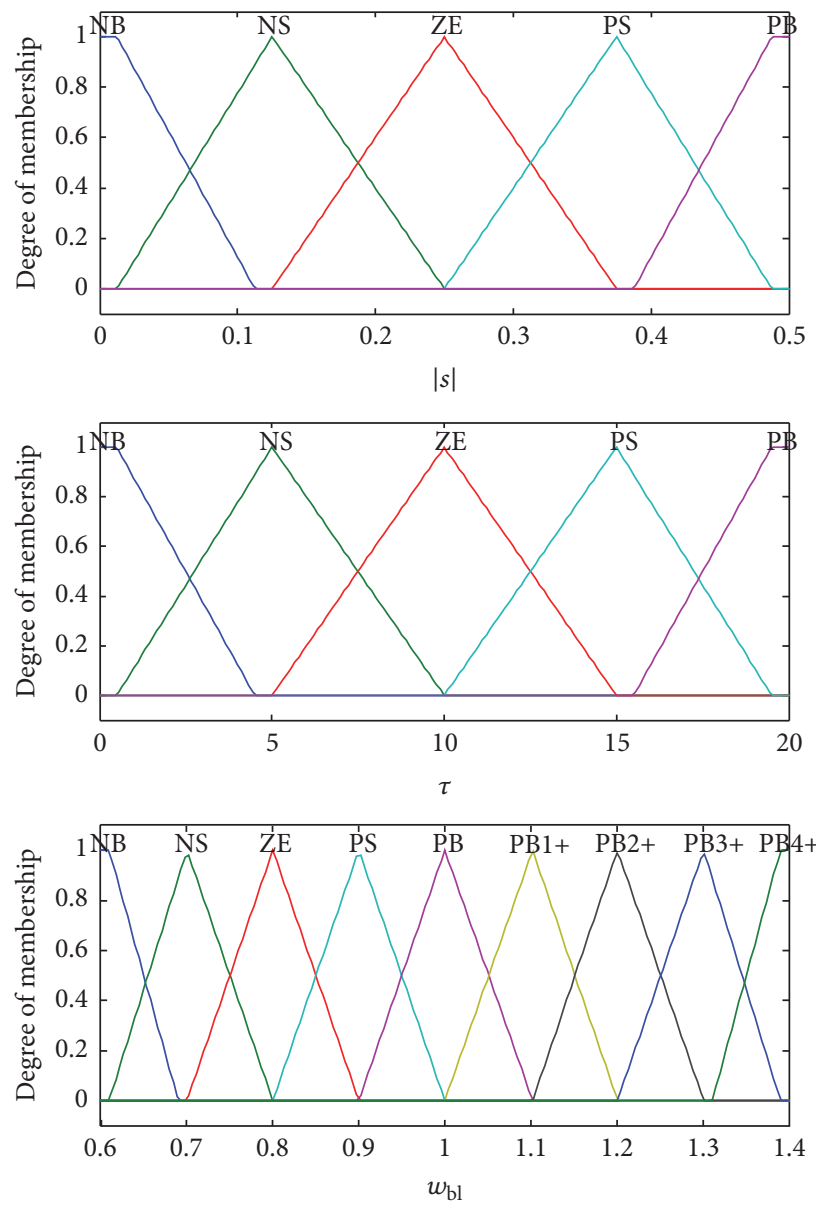

FIGURE 7: Membership functions for three variables.

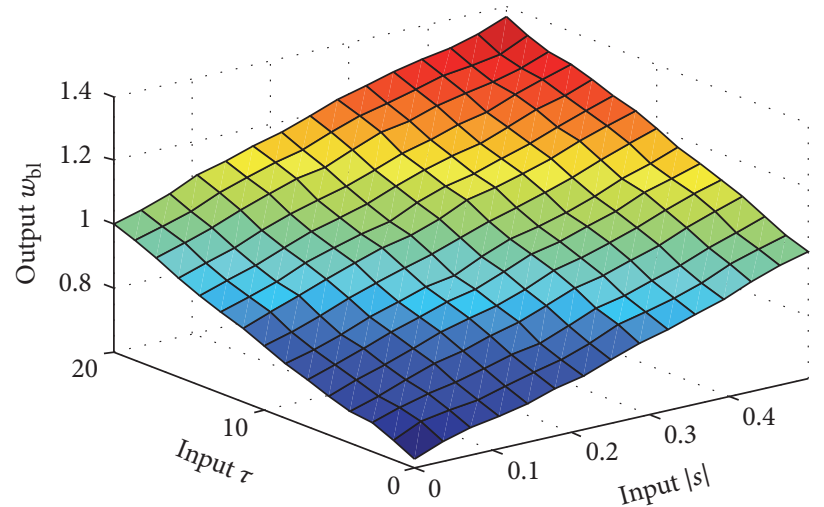

FIgURE 8: The rule relations between the inputs and the outputs for the proposed controller.

Generally, the feedback link delay $\sigma_{k}$ in a NCS is known, which can be measured by using a "time sampling technology" with the time tag within each received message sent by sensor node. However, the current delay $d_{k}$ in the forward link cannot be measured. In this paper, a "delay estimating technology," which is based on Network Calculus Theory [24], is introduced to estimate the forward link delay $d_{k}$ with an explicit expression as follows [24]:

$$
\tau_{\text {large }, j}=\frac{(j+2) l}{R-\sum_{i=0}^{j-1}\left(l / c_{i}\right)},
$$




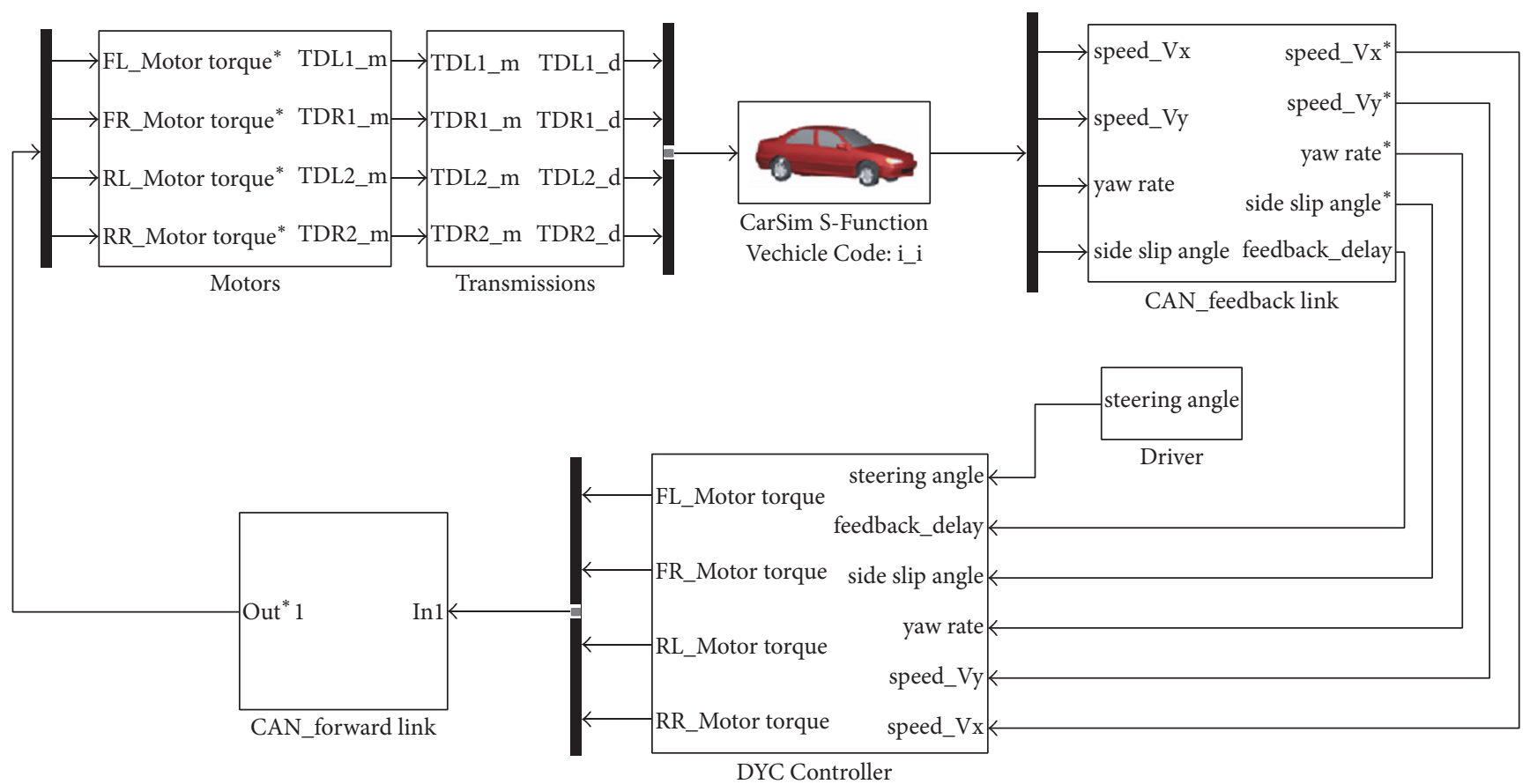

FIgURE 9: The cosimulation model with Simulink and CarSim.

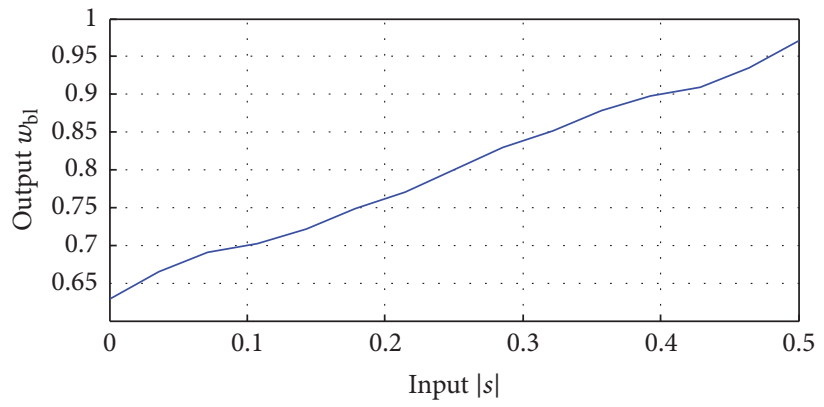

FIGURE 10: The rule relations between the input and the output for conventional FSMC.

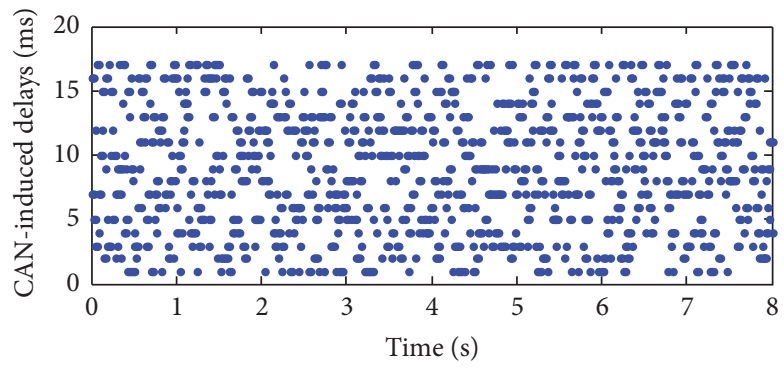

FIGURE 11: The network-induced delays in control loop over CAN. 


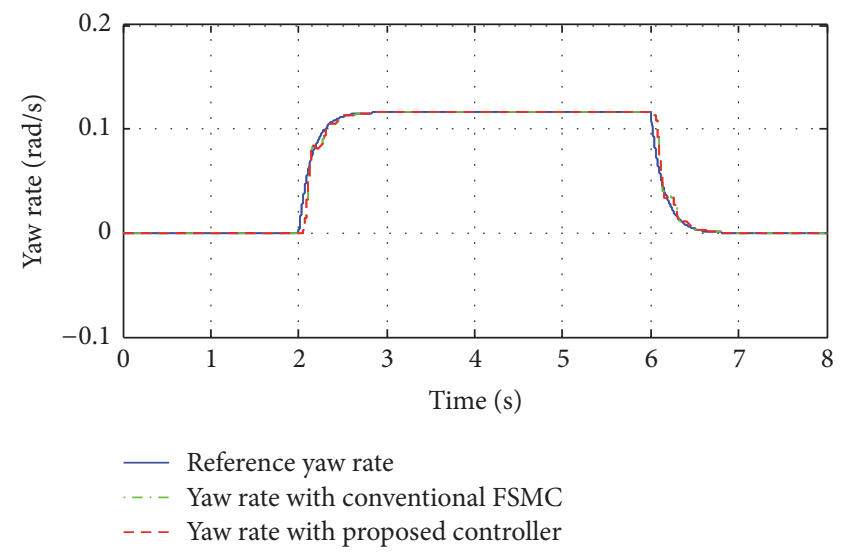

(a)

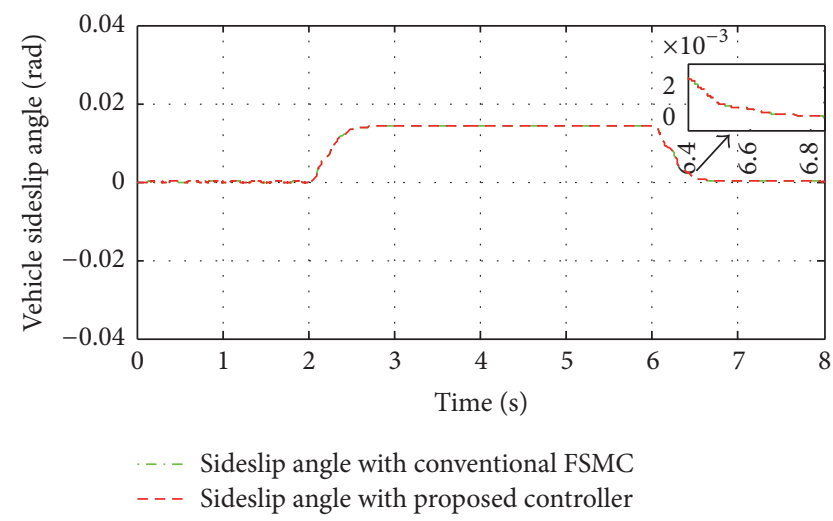

(b)

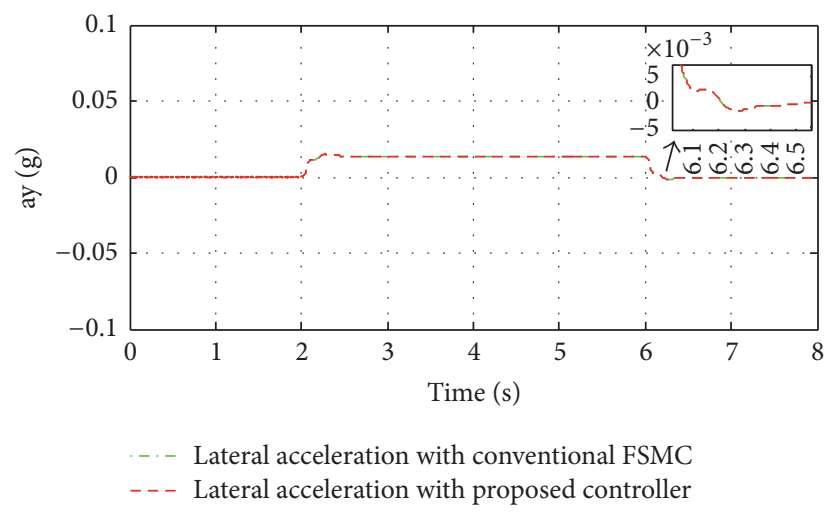

(c)

FIGURE 12: Control performance in J-turn maneuver under the ideal network condition. (a) Vehicle yaw rate. (b) Vehicle sideslip angle. (c) Vehicle lateral acceleration.

where $\tau_{\text {large, } j}$ is the upper bound of delay of a message with the $j$ th priority sent by CAN; $l$ indicates the maximum data frame length; $R$ is the baud rate of the CAN; $c_{i}$ is the cycle length of the message with the $i$ th priority.

According to the research result in [24], the networkedinduced delay of the message with the highest priority sent by CAN network can be accurately estimated through the expression (27). Therefore, this paper uses a "command-first scheme," in which the command message in the forward link is sent with the highest priority to ensure the accuracy of $d_{k}$ as follows:

$$
d_{k}=\tau_{\text {large }, j}=\frac{(j+2) l}{R-\sum_{i=0}^{j-1}\left(l / c_{i}\right)}, \quad \text { setting } j=0
$$

Thus, the network-induced delay $\tau_{k}$ can be precisely determined by the following formula:

$$
\tau_{k}=\sigma_{k}+\frac{(j+2) l}{R-\sum_{i=0}^{j-1}\left(l / c_{i}\right)}, \quad \text { setting } j=0
$$

TABLE 3: Main vehicle parameters.

\begin{tabular}{lcc}
\hline Parameter & Description & Quantity \\
\hline$M$ & Vehicle mass & $1350 \mathrm{~kg}$ \\
$I_{Z}$ & Yaw moment of inertia & $1975 \mathrm{~kg} \cdot \mathrm{m}^{2}$ \\
$l_{f}$ & Front semiwheelbase & $1.085 \mathrm{~m}$ \\
$l_{r}$ & Rear semiwheelbase & $1.386 \mathrm{~m}$ \\
$c_{f}$ & Cornering stiffness of front tires & $58000 \mathrm{~N} / \mathrm{rad}$ \\
$c_{r}$ & Cornering stiffness of rear tires & $60000 \mathrm{~N} / \mathrm{rad}$ \\
\hline
\end{tabular}

\section{Simulation Results}

To study the effectiveness of the proposed controller, the cosimulations are carried out in Matlab/Simulink with a fullvehicle model constructed by CarSim (see Figure 9). The vehicle parameters used in the simulations are based on a prototyped 4WID-EV, and main parameters are listed in Table 3.

The proposed controller is used in motion controller unit (see Figure 1) and a simple torque distribution strategy, which distributes the direct yaw-moment equally to the driving or braking torques of 4 wheels, is used in torque distribution 


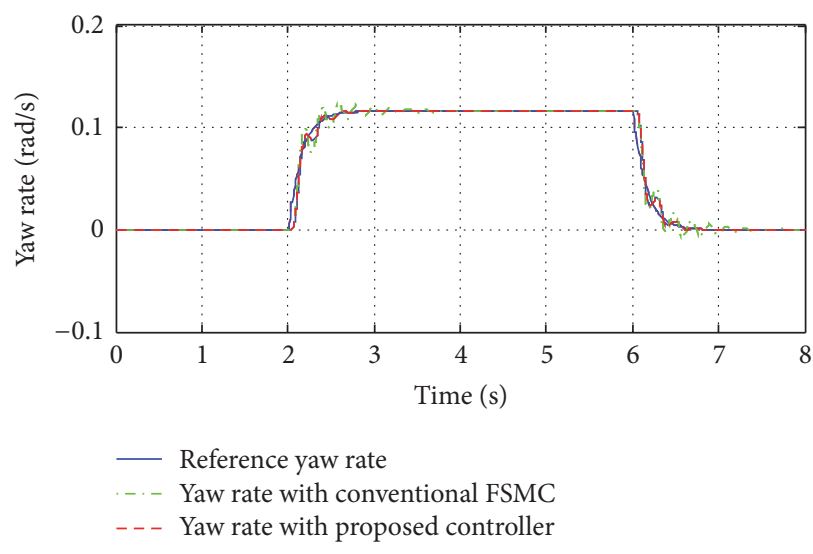

(a)

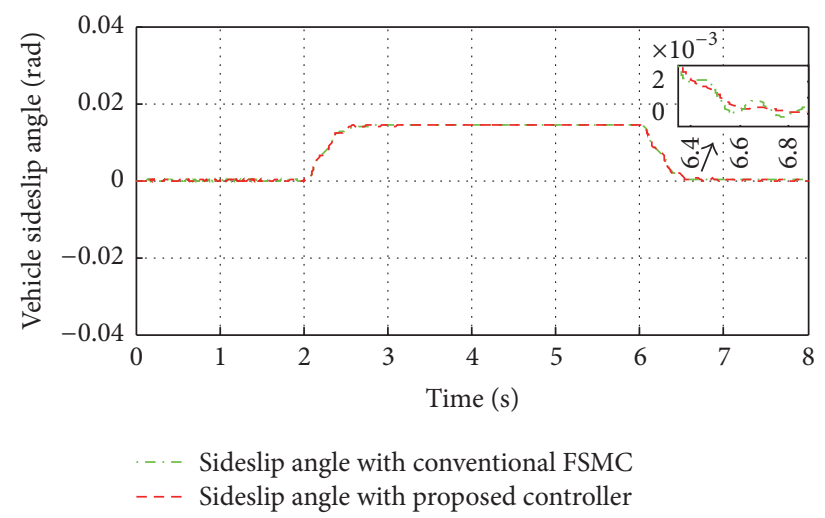

(b)

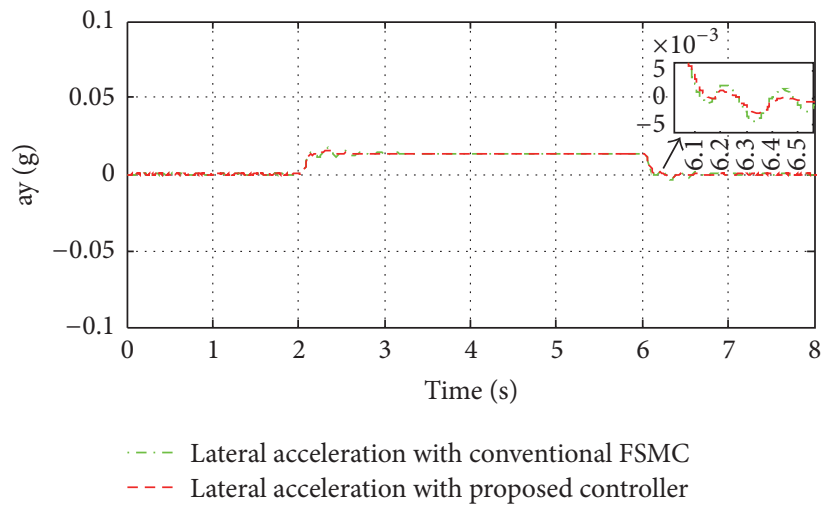

(c)

FIGURE 13: Control performance in J-turn maneuver with the network-induced delays caused by CAN. (a) Vehicle yaw rate. (b) Vehicle sideslip angle. (c) Vehicle lateral acceleration.

unit (see Figure 1). For comparison, a conventional statedependent fuzzy SMC controller (the conventional FSMC) without considering network-induced delays is also designed. And the designed rule base of the conventional FSMC is shown in Figure 10.

The reaching law parameters of SMC are chosen as $\varepsilon=$ 27.5 and $q=0$. According to the results in [22], the upper bound of network-induced delays in a practical vehicle control system is about as high as $1.7 T_{s}$. The sampling period of the closed-loop system is adopted as $T_{s}=10 \mathrm{~ms}$. Thus, CAN-induced delays in simulations are assumed to change randomly in time range $\left[0,1.7 T_{s}\right]$ (see Figure 11 ).

Two different steering maneuvers, which are commonly used in vehicle tests, are considered: a ramp steering maneuver and a double lane-changing maneuver. The ramp steering maneuver is often adopted in the $J$-turn test and the double lane-changing maneuver is usually used in extreme cases, for example, high-speed overtaking or obstacle avoidance.

In each driving maneuver, simulations are carried out in two stages. The first stage is under the ideal network condition to evaluate the effectiveness of controllers without considering network-induced delays. The second stage is to verify the robustness of the proposed controller with network-induced delays.

4.1. J-Turn Steering Maneuver. In this case, the vehicle runs at a low speed of $40 \mathrm{~km} / \mathrm{h}$ on a slippery road with a low road friction $(\mu=0.4)$. During the $J$-turn maneuver, the steering wheel angle first increases from 0 deg to $18 \mathrm{deg}$ in $0.5 \mathrm{~s}$, which is used to simulate a sharp turn. Then it decreases to 0 deg again in $4 \mathrm{~s}$.

Figure 12 shows the results of cosimulations in the $J$ turn steering maneuver under the ideal network condition. It is obvious in Figures 12(a), 12(b), and 12(c) that the vehicle yaw rate can precisely track the desired reference by the driver, the vehicle sideslip angle can be restrained in a narrow scope around $0.014 \mathrm{rad}$, and the lateral acceleration can be restrained in a narrow scope around $0.013 \mathrm{~g}$. For the two controllers, the control performance is satisfactory. The results demonstrate the effectiveness of the conventional FSMC and the proposed controller.

Figure 13 shows the results of cosimulations in the $J$-turn steering maneuver with the network-induced delays caused by CAN. It is obvious in Figures 13(a), 13(b), and 13(c) that, with the conventional FSMC, the vehicle motion cannot track 

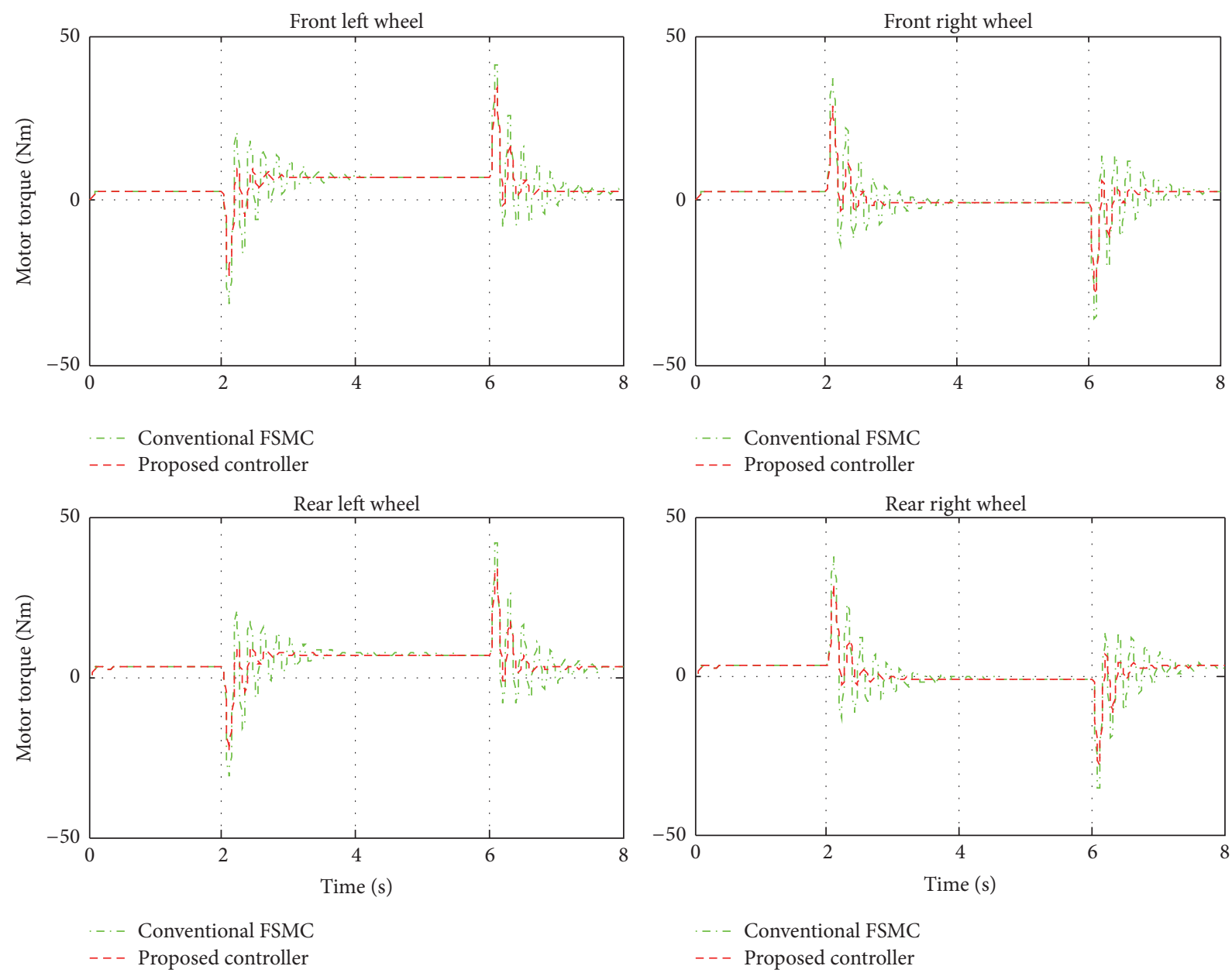

Figure 14: Motor torques of 4 wheels with two different controllers for DYC of 4WID-EV in double $J$-turn maneuver with the networkinduced delays caused by CAN.

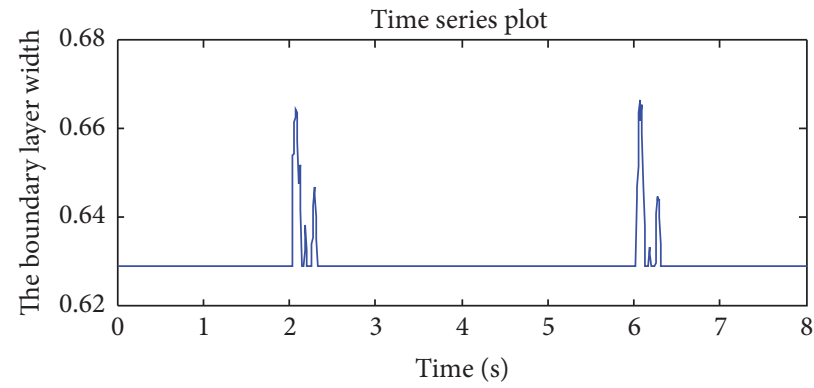

FIGURE 15: Tuning the boundary layer width process by the conventional FSMC in double $J$-turn steering maneuver with the network-induced delays caused by CAN.

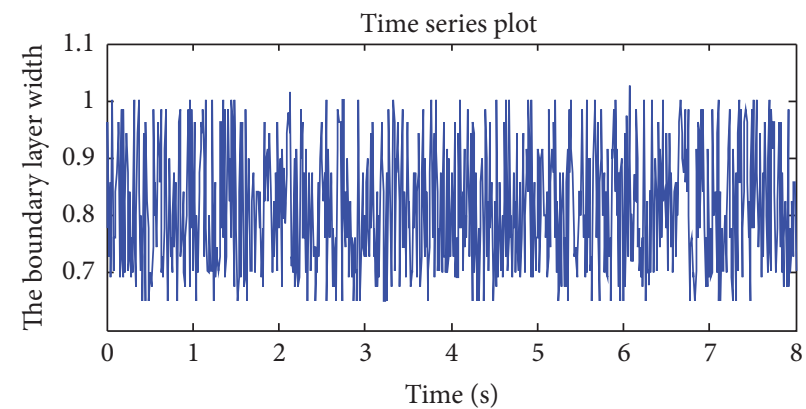

FIGURE 16: Tuning the boundary layer width process by the proposed controller in double $J$-turn steering maneuver with the network-induced delays caused by CAN. 


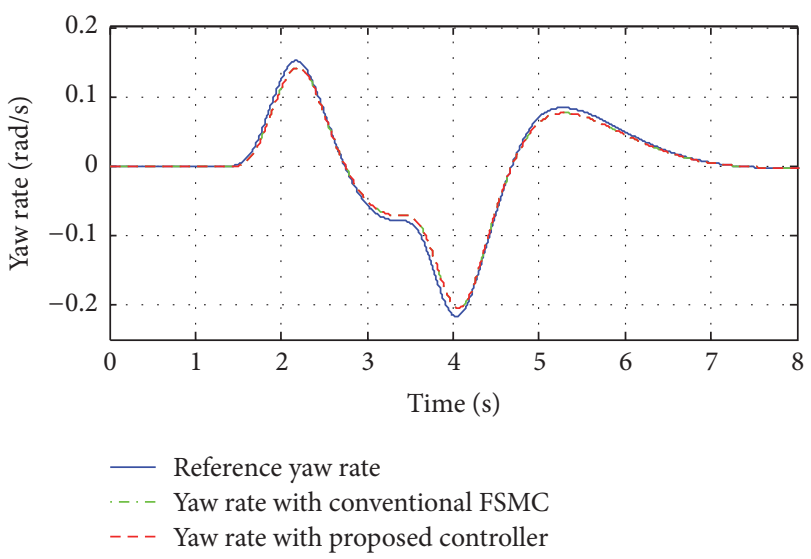

(a)

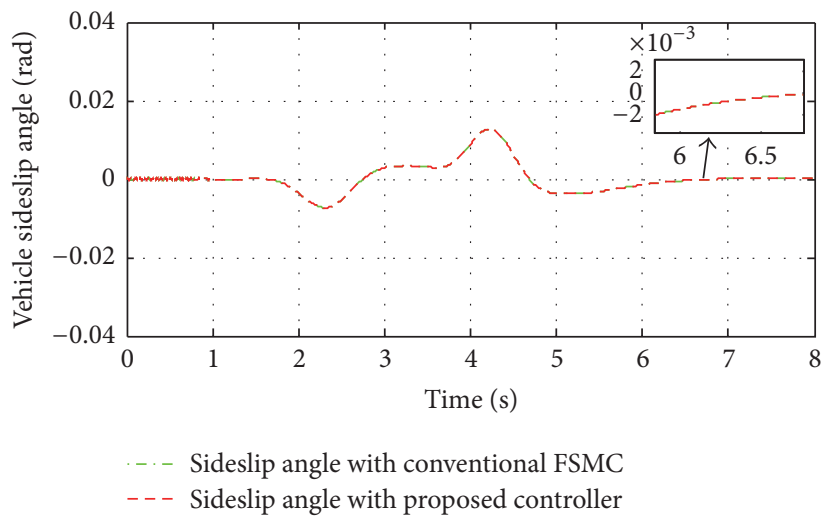

(b)

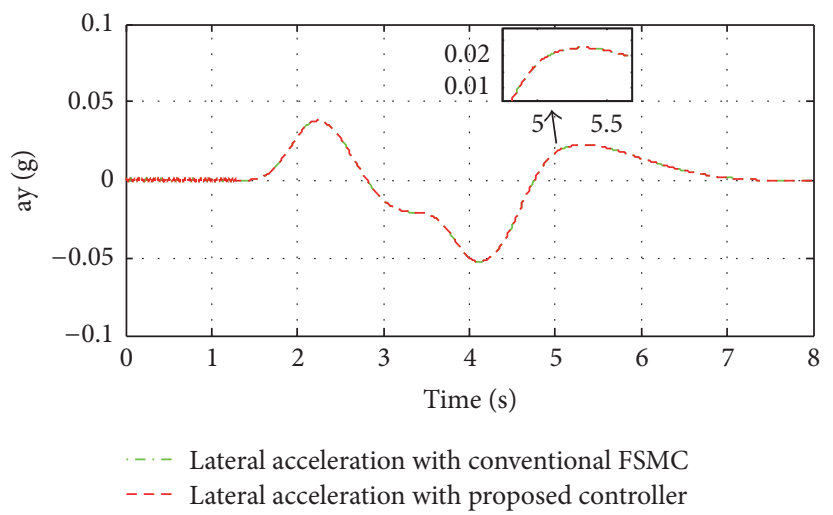

(c)

FIGURE 17: Control performance in double lane-changing maneuver under the ideal network condition. (a) Vehicle yaw rate. (b) Vehicle sideslip angle. (c) Vehicle lateral acceleration.

the desired yaw rate in the transient phase but can keep tracking the desired yaw rate in the steady phase, and the yaw rate overshoot is about $10.3 \%$ in the transient phase, while, for the proposed controller, the adverse impact of delays can be eliminated and the control performance is still satisfactory. The yaw rate overshoot is about 3.4\%. Therefore the results of comparison explicitly illustrate the strength of the proposed controller dealing with network-induced delays.

Figure 14 shows the torque response of 4 motors in the $J$-turn steering maneuver with the network-induced delays caused by CAN. It is obvious that, with the conventional FSMC, the chattering phenomenon of each motor is severe in the transient phase, which would reduce control performance of DYC and even deteriorate the EV system, while, for the proposed controller, the performance of the torque response of each motor is satisfactory.

Figures 15 and 16 show the dynamic boundary layers of two controllers in the $J$-turn steering maneuver with the network-induced delays caused by CAN.

The results show that the conventional FSMC can tune the boundary layer width according to the vehicle states but not the network-induced delays. The proposed controller can tune the boundary layer width according to both the vehicle states and the network-induced delays.
4.2. Double Lane-Changing Steering Maneuver. In this case, the vehicle runs at a high speed of $100 \mathrm{~km} / \mathrm{h}$ on a road with a high road friction $(\mu=0.85)$.

The following cosimulation process is quite similar to that for the $J$-turn steering maneuver. Under different network conditions, the results are shown in Figures 17, 18, 19, 20, and 21. Under the ideal network condition, the actual vehicle yaw rate can track the desired reference very well, and the vehicle sideslip angle and the vehicle lateral acceleration can also be kept regulated for both controllers. When with the networkinduced delays, the proposed control can still keep the vehicle yaw rate tracking the desired reference very well, whereas the conventional FSMC results in significant oscillations due to the effect of the network-induced delays. Furthermore, a similar observation can be found in the vehicle sideslip angle and the vehicle lateral acceleration. The torque response of each motor is also shown as in Figure 19. The results show that network-induced delays have a significant impact on the stability of the closed-loop control system and can obviously reduce the robustness of the conventional FSMC.

The tuning boundary layer width processes of two controllers in double lane-changing maneuver are shown in Figures 20 and 21 . The results also show that the conventional FSMC only can tune the boundary layer width according to 


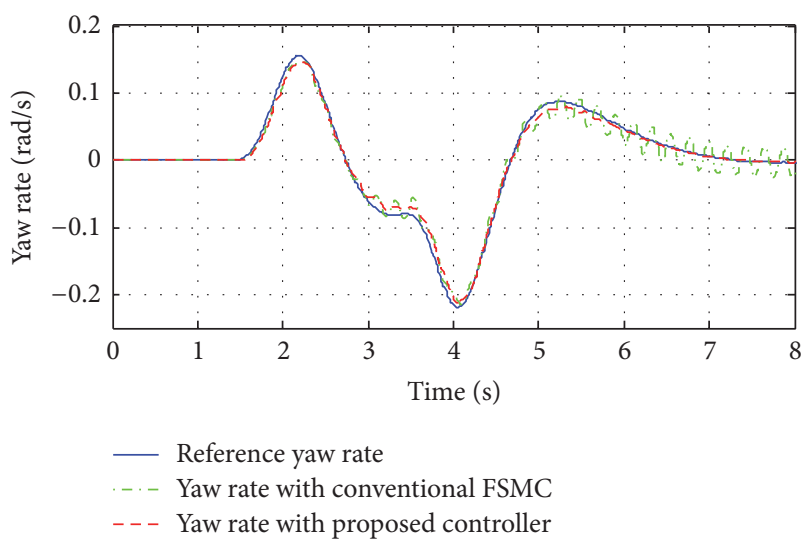

(a)

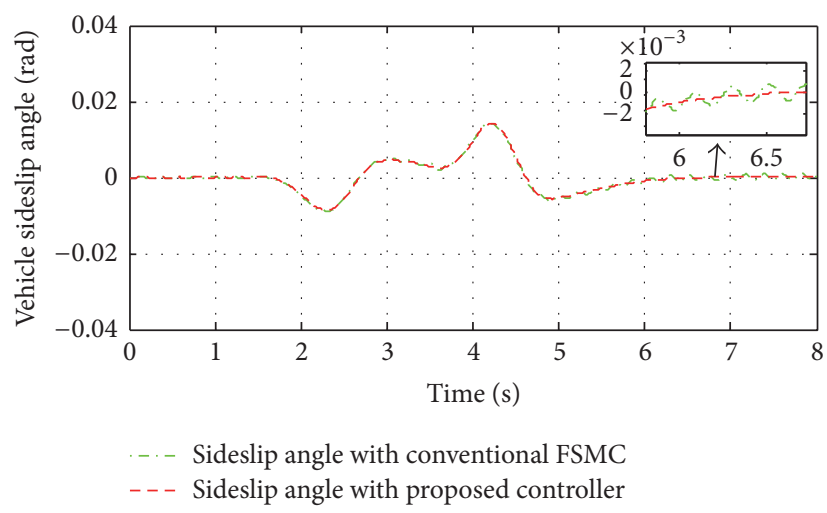

(b)

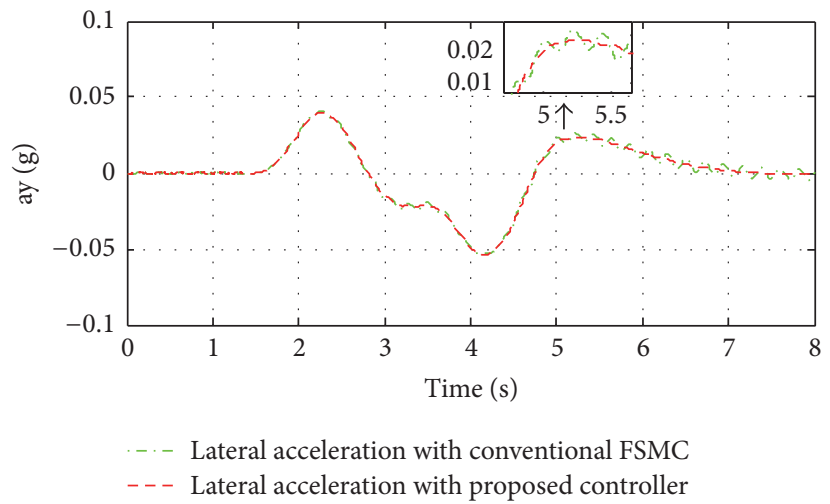

(c)

FIGURE 18: Control performance in double lane-changing maneuver with the network-induced delays caused by CAN. (a) Vehicle yaw rate. (b) Vehicle sideslip angle. (c) Vehicle lateral acceleration.

the vehicle states but not the network-induced delays, while the proposed controller can tune the boundary layer width actively according to both the vehicle states and the system delays, which makes the control system more robust.

\section{Conclusions}

This paper proposed an integrated state-dependent and delay-dependent fuzzy sliding mode control method to improve the robustness of DYC of AWID-EVs subject to network-induced delays. The SMC, which can effectively deal with model uncertainties, system parameter variations, and external disturbances, has been widely used to improve the robustness of DYC of AWID-EVs instead of common continuous control technologies such as LQR and PID. However, on the other hand, the SMC, which is a variable structure control, is more vulnerable to the system delays from electronic control systems. Meanwhile, in modern AWID-EVs, the networked control system based on in-vehicle networks such as CAN would inevitably impose network-induced delays on the vehicle control system. In order to improve the robustness of DYC of AWID-EVs, this paper first analyzed the adverse impact resulted from NCS on DYC based on SMC in detail.
Then an integrated state-dependent and delay-dependent fuzzy SMC method is proposed to improve the robustness of DYC for AWID-EVs.

The results of comparison in both typical steering maneuver cases show that the proposed controller can effectively improve the robustness of DYC for AWID-EVs subject to network-induced delays. Moreover, the proposed controller also inherits the robustness of SMC in terms of dealing with model uncertainties, system parameter variations, and external disturbances.

\section{Competing Interests}

The authors declare that they have no competing interests.

\section{Acknowledgments}

This work was supported in part by the National Natural Science Foundation of China (Grants 51205022, 51575044), the National Key Technology Support Program of China (Grant 2014BAG02B02), the China-Poland Collaborative Project of Electric City Bus (Grant 2015DFG81930), and the Basic Research Foundation of BIT (Grant 20140342015). 

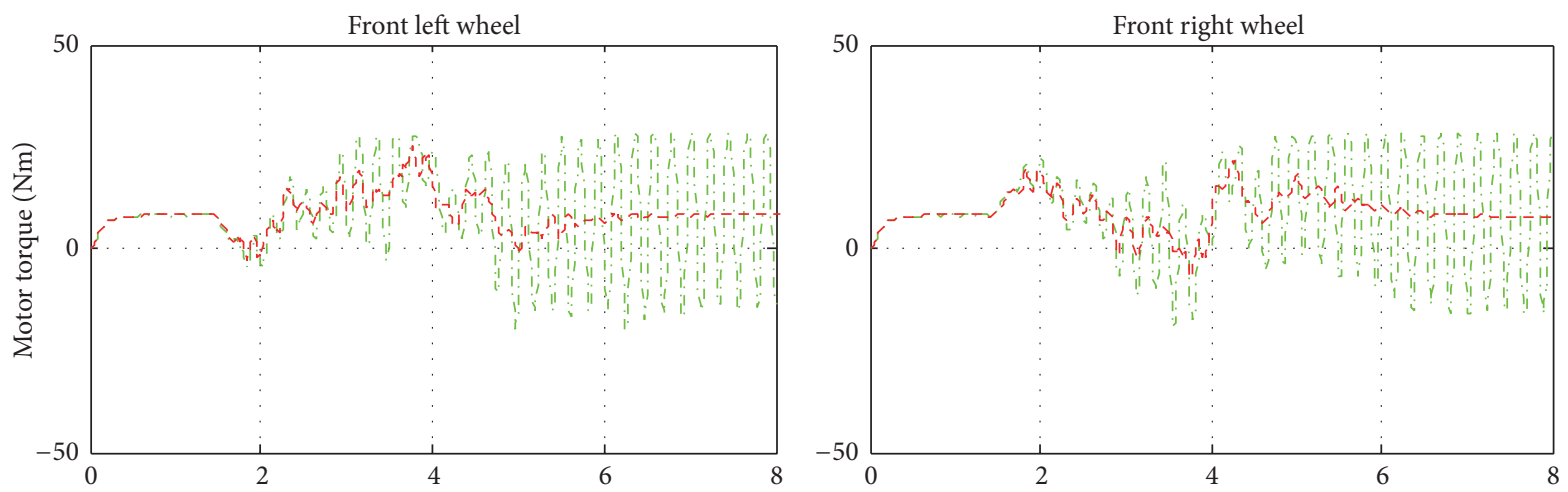

-..- Conventional FSMC

-..- Conventional FSMC

-- - Proposed controller

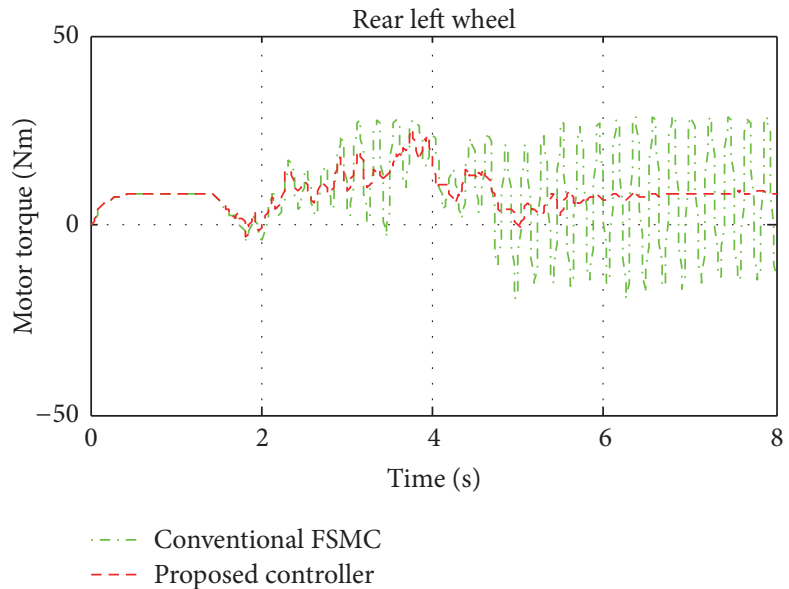

- - - Proposed controller

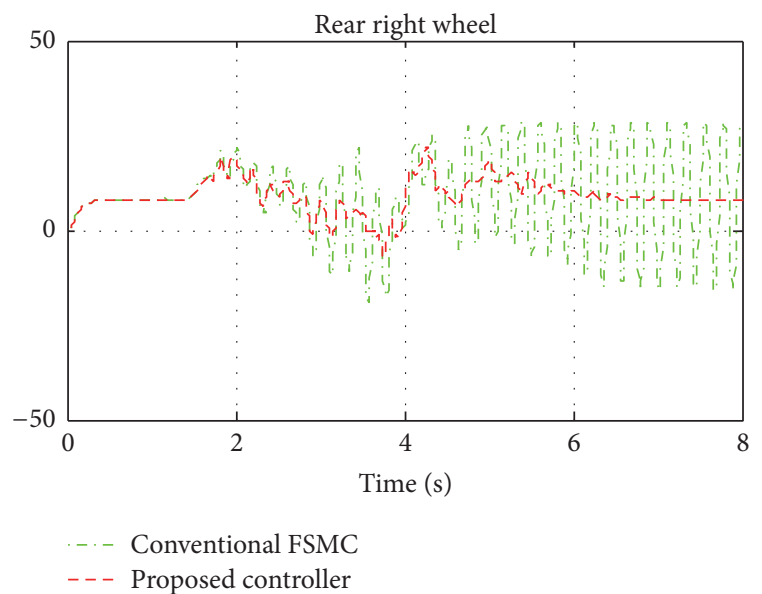

FIgURE 19: Motor torques of 4 wheels with two different controllers for DYC of 4 WID-EV in double lane-changing maneuver with the network-induced delays caused by CAN.

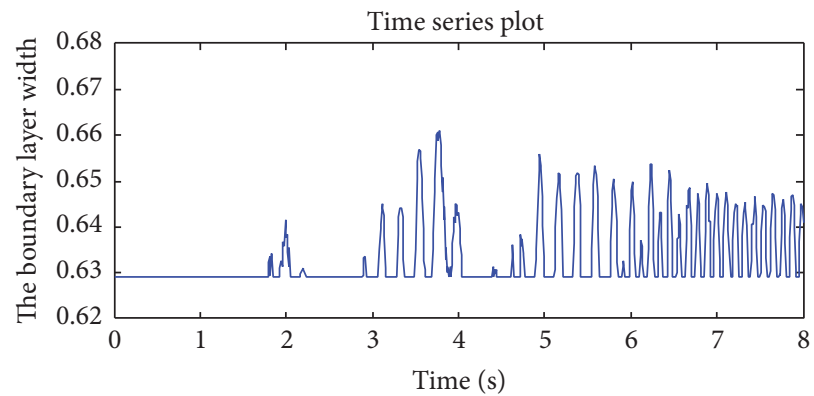

FIGURE 20: Tuning the boundary layer width process by the conventional FSMC in double lane-changing steering maneuver with the networkinduced delays caused by CAN.

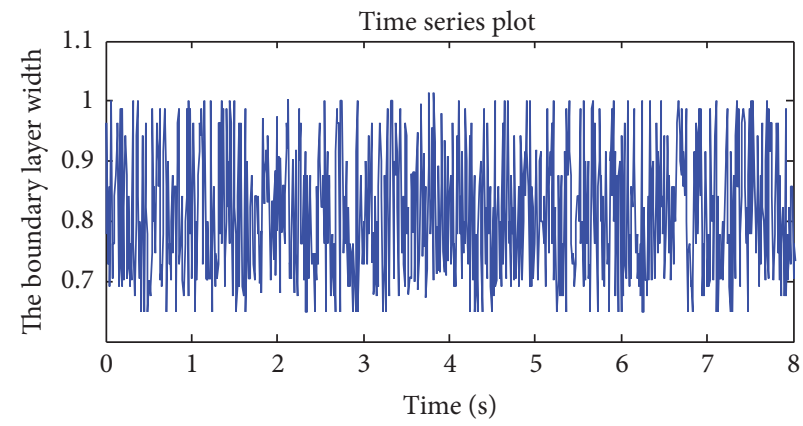

FIGURE 21: Tuning the boundary layer width process by the proposed controller in double lane-changing steering maneuver with the networkinduced delays caused by CAN. 


\section{References}

[1] A. Goodarzi and E. Esmailzadeh, "Design of a VDC system for all-wheel independent drive vehicles," IEEE/ASME Transactions on Mechatronics, vol. 12, no. 6, pp. 632-639, 2007.

[2] Z. Shuai, H. Zhang, J. Wang, J. Li, and M. Ouyang, "Combined AFS and DYC control of four-wheel-independent-drive electric vehicles over CAN Network with time-varying delays," IEEE Transactions on Vehicular Technology, vol. 63, no. 2, pp. 591-602, 2014.

[3] Y. H. Shen, Y. Gao, and T. Xu, "Multi-axle vehicle dynamics stability control algorithm with all independent drive wheel," International Journal of Automotive Technology, vol. 17, no. 5, pp. 795-805, 2016.

[4] L. De Novellis, A. Sorniotti, P. Gruber et al., "Direct yaw moment control actuated through electric drivetrains and friction brakes: theoretical design and experimental assessment," Mechatronics, vol. 26, pp. 1-15, 2015.

[5] R. Wang, C. Hu, F. Yan, and M. Chadli, "Composite nonlinear feedback control for path following of four-wheel independently actuated autonomous ground vehicles," IEEE Transactions on Intelligent Transportation Systems, vol. 17, no. 7, pp. 2063-2074, 2016.

[6] L. Xiong, G. W. Teng, Z. P. Yu, W. X. Zhang, and Y. Feng, "Novel stability control strategy for distributed drive electric vehicle based on driver operation intention," International Journal of Automotive Technology, vol. 17, no. 4, pp. 651-663, 2016.

[7] G. Qin and J. Zou, " $\mathrm{H}_{\infty}$ control of four-wheel-independentdrive electric vehicles with random time-varying delays," Mathematical Problems in Engineering, vol. 2015, Article ID 245493, 10 pages, 2015.

[8] R. Wang and J. Wang, "Fault-tolerant control with active fault diagnosis for four-wheel independently driven electric ground vehicles," IEEE Transactions on Vehicular Technology, vol. 60, no. 9, pp. 4276-4287, 2011.

[9] Z. Shuai, H. Zhang, J. Wang, J. Li, and M. Ouyang, "Lateral motion control for four-wheel-independent-drive electric vehicles using optimal torque allocation and dynamic message priority scheduling," Control Engineering Practice, vol. 24, no. 1, pp. 55-66, 2014.

[10] X. Zhu, H. Zhang, J. Wang, and Z. Fang, "Robust lateral motion control of electric ground vehicles with random networkinduced delays," IEEE Transactions on Vehicular Technology, vol. 64, no. 11, pp. 4985-4995, 2015.

[11] H. Alipour, M. Sabahi, and M. B. B. Sharifian, "Lateral stabilization of a four wheel independent drive electric vehicle on slippery roads," Mechatronics, vol. 30, pp. 275-285, 2015.

[12] Y. Hori, Y. Toyoda, and Y. Tsuruoka, "Traction control of electric vehicle: basic experimental results using the test EV 'UOT electric march"' IEEE Transactions on Industry Applications, vol. 34, no. 5, pp. 1131-1138, 1998.

[13] S.-I. Sakai, H. Sado, and Y. Hori, "Motion control in an electric vehicle with four independently driven in-wheel motors," IEEE/ASME Transactions on Mechatronics, vol. 4, no. 1, pp. 9$16,1999$.

[14] D. Li, S. Du, and F. Yu, "Integrated vehicle chassis control based on direct yaw moment, active steering and active stabiliser," Vehicle System Dynamics, vol. 46, no. 1, pp. 341-351, 2008.

[15] J. Wang and R. G. Longoria, "Coordinated and reconfigurable vehicle dynamics control," IEEE Transactions on Control Systems Technology, vol. 17, no. 3, pp. 723-732, 2009.
[16] D. B. Ren, J. Y. Zhang, J. M. Zhang, and S. M. Cui, “Trajectory planning and yaw rate tracking control for lane changing of intelligent vehicle on curved road," Science China Technological Sciences, vol. 54, no. 3, pp. 630-642, 2011.

[17] P. Song, C.-F. Zong, and M. Tomizuka, "A terminal sliding mode based torque distribution control for an individual-wheel-drive vehicle," Journal of Zhejiang University: Science A, vol. 15, no. 9, pp. 681-693, 2014.

[18] W. Gao, Y. Wang, and A. Homaifa, "Discrete-time variable structure control systems," IEEE Transactions on Industrial Electronics, vol. 42, no. 2, pp. 117-122, 1995.

[19] S. Z. Sarpturk, Y. Istefanopulos, and O. Kaynak, "On the stability of discrete-time sliding mode control systems," IEEE Transactions on Automatic Control, vol. 32, pp. 930-932, 1987.

[20] M.-S. Chen, Y.-R. Hwang, and M. Tomizuka, "A state dependent boundary layer design for sliding mode control," Institute of Electrical and Electronics Engineers. Transactions on Automatic Control, vol. 47, no. 10, pp. 1677-1681, 2002.

[21] B. L. Boada, M. J. L. Boada, and V. Díaz, "Fuzzy-logic applied to yaw moment control for vehicle stability," Vehicle System Dynamics, vol. 43, no. 10, pp. 753-770, 2005.

[22] C. F. Caruntu, M. Lazar, R. H. Gielen, P. P. J. van den Bosch, and S. Di Cairano, "Lyapunov based predictive control of vehicle drivetrains over CAN," Control Engineering Practice, vol. 21, no. 12, pp. 1884-1898, 2013.

[23] N. Yagiz, Y. Hacioglu, and Y. Taskin, "Fuzzy sliding-mode control of active suspensions," IEEE Transactions on Industrial Electronics, vol. 55, no. 11, pp. 3883-3890, 2008.

[24] T. Herpel, K.-S. Hielscher, U. Klehmet, and R. German, "Stochastic and deterministic performance evaluation of automotive CAN communication," Computer Networks, vol. 53, no. 8, pp. 1171-1185, 2009. 


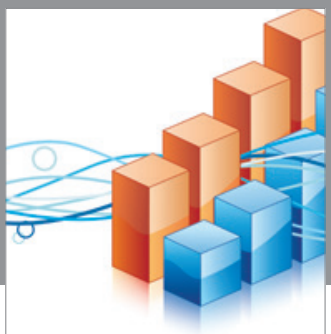

Advances in

Operations Research

vatem alat4

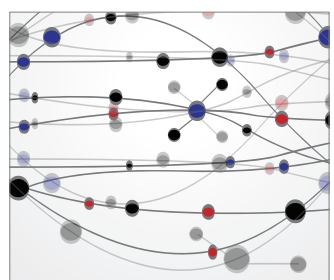

\section{The Scientific} World Journal
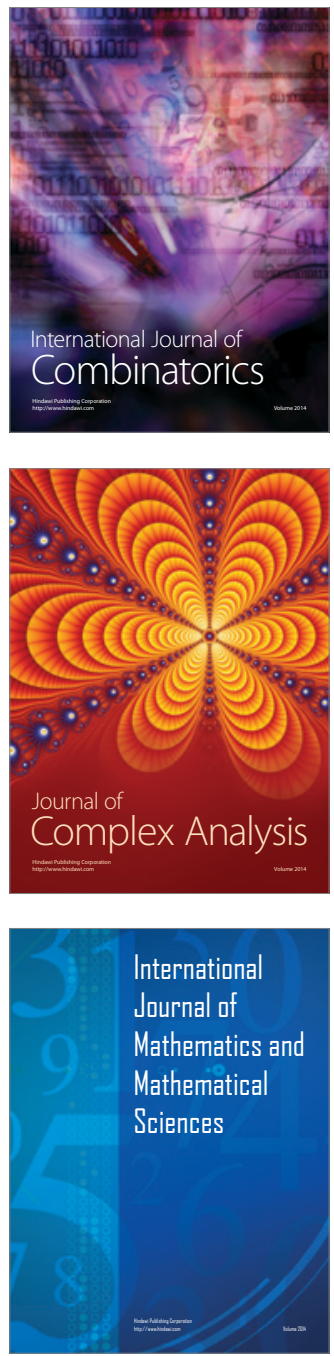
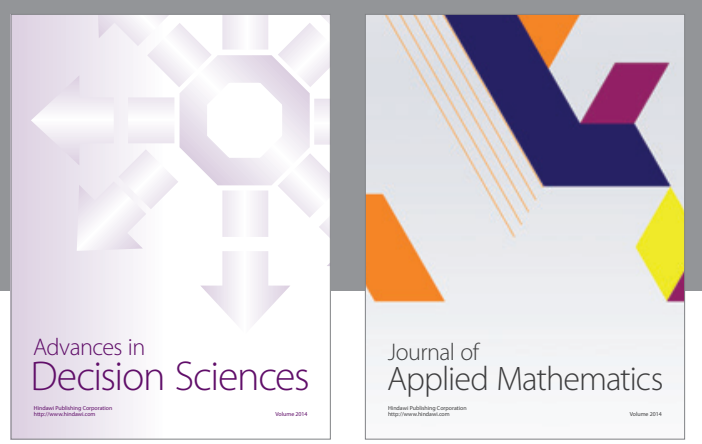

Algebra

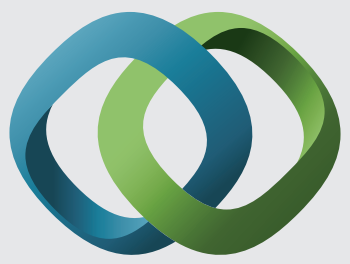

\section{Hindawi}

Submit your manuscripts at

https://www.hindawi.com
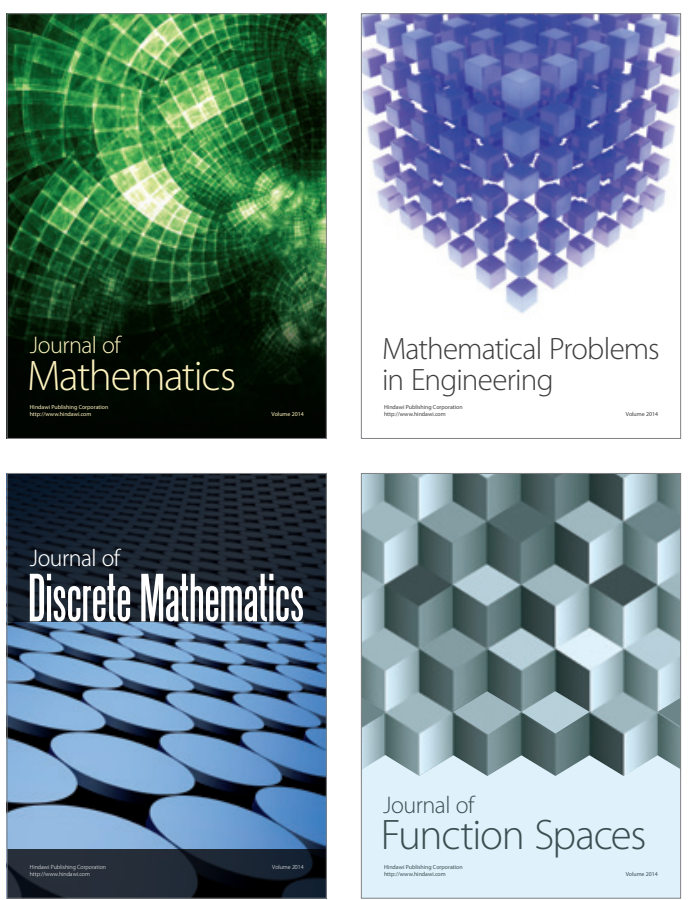

Mathematical Problems in Engineering
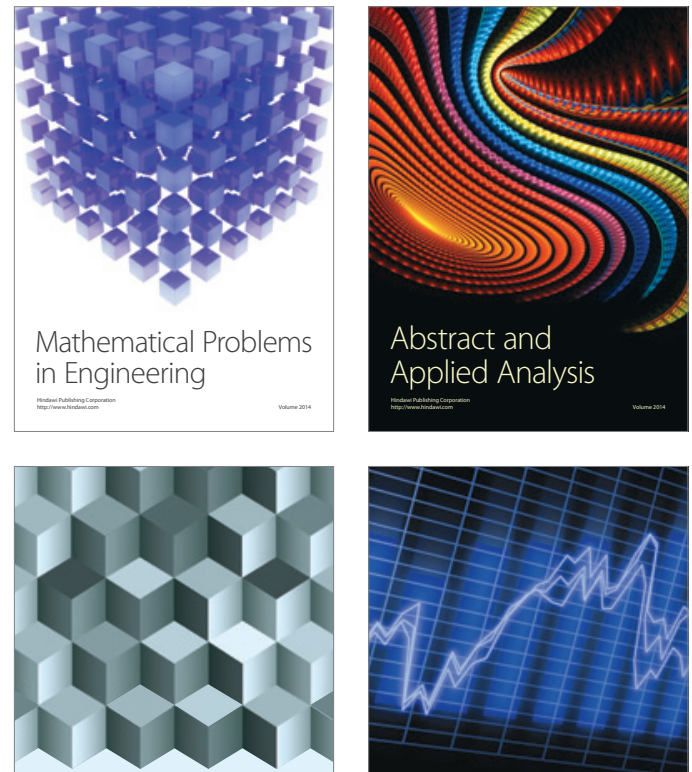

Journal of

Function Spaces

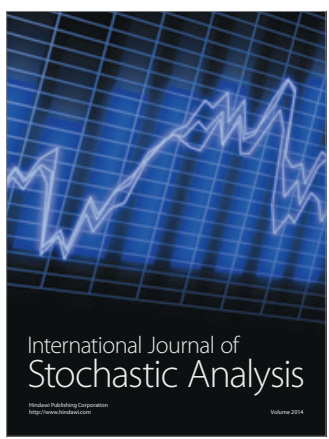

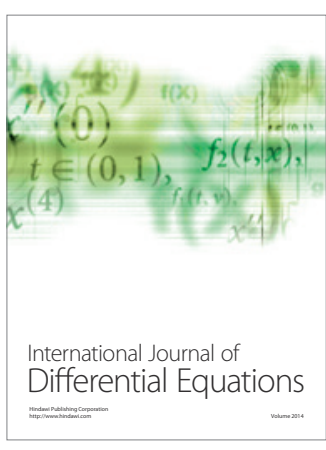
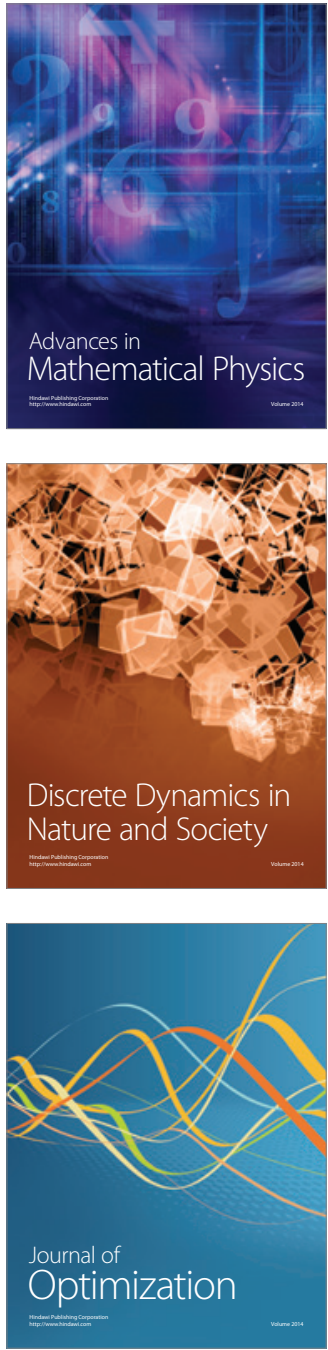